\title{
Urban transformation and heat island: Potential of urban design alternatives to mitigate the effects of urban overheating in Austrian cities
}

\author{
M.Vuckovic ${ }^{a *}$, T. Tötzer ${ }^{\mathrm{a}}$, R. Stollnberger ${ }^{\mathrm{a}}$, W.Loibl ${ }^{\mathrm{a}}$
}

${ }^{a}$ AIT Austrian Institute of Technology GmbH, Giefinggasse 4, 1210 Vienna, Austria.

Email: tanja.toetzer@ait.ac.at; romana.stollnberger@ait.ac.at; wolfgang.loibl@ait.ac.at

Received: 30 August 2019 / Revised: 04 February 2020 / Accepted: 03 March 2020

\begin{abstract}
Ongoing urbanization worldwide present a big challenge for the quality of urban life. This development poses great challenges for cities due to the growing demand for more living space and supporting infrastructure, resulting in environmental pollution, higher anthropogenic waste heat and poor outdoor thermal comfort. To accommodate this rapid expansion of urban areas, the city authorities need to adopt a more climate-sensitive approach to urban transformation. In this regard, the present contribution investigates the potential of specific planning and adaptation strategies to attenuate the urban overheating for distinct urban locations in Vienna and Linz, Austria, over a hot summer period. For this purpose, we applied the parametric modelling environment Rhinoceros 3D and a number of built-in algorithms in the Rhino's plug-in Grasshopper for dynamic simulation of urban microclimate. The results were compared based on the mean radiant temperature (MRT) averaged over a 24-hour cycle and differentiated into day- and night-time shares. The results reveal a notable potential of selected greening measures to positively influence outdoor thermal conditions. The effectiveness of these measures, however, seem to be time-dependent, whereby a more pronounced cooling effect was noted during the daytime, attributed to the solar shielding effect.
\end{abstract}

\section{Keywords:}

Urban Climate, Urban Heat Island, Climate Modelling, Adaptation Strategies, Urban Greening.

(c) Euraass 2020. All rights reserved.

\section{Introduction}

The past century has seen a major shift of population towards urban areas, resulting in rapid urbanization worldwide (UN 2019). The cities of today are thus facing numerous transformation challenges, some of these being urban sprawl and densification, due to the growing demand for more living space. Moreover, this calls for a significant development in supporting infrastructure (e.g., transportation network, heating/cooling systems, water supply). The environmental pollution, higher anthropogenic waste heat and poor outdoor thermal comfort

*Corresponding author: E-mail: milena.vuckovic@ait.ac.at (M.Vuckovic).

Available online: $30^{\text {th }}$ March 2020

DOI: https://doi.org/10.34154/2020-JUE-0101-03-14/euraass

Journal reference: J. Urban Env. 2020, 01(01), 03 - 14.

ISSN-E: 2726-0844.

(c) European Academy of Applied and Social Sciences. Euraass - 2020. All rights reserved.

Cite as: Vuckovic, M., Tötzer, T., \& Stollnberger, R., \& Loibl, W. (2020). Urban transformation and heat island: Potential of urban design alternatives to mitigate the effects of urban overheating in Austrian cities. J. Urban Env. 01(01), 03- 14. 
are just a few of the resulting implications of such developments, which critically affect the quality of urban life (Flanner 2009; Petrović et al., 2016; Nazarian, 2018). For example, Flanner (2009) argued that once the anthropogenic heat flux, that originates from human activity, reaches levels greater than $3 \mathrm{Wm}^{-2}$, it may contribute to significant warming tendencies in local climate. Just for a comparison, according to the Climate and Global Dynamics Laboratory (CGD), a part of the National Center for Atmospheric Research (NCAR), the 2005 annual mean anthropogenic heat flux for the area of Austria was in the range of 0.6 to $1.6 \mathrm{Wm}^{-2}$ (CGD 2019). The effects of these environmental impacts are becoming even more severe with a massive transition of pervious into impervious cover, which results from the need to accommodate a growing population. Due to the high pressure for new living space this is often done using conventional high heatabsorbing materials resulting in high surface temperatures that greatly contribute to the formation of urban heat island (UHI) (Ma et al., 2016, Estoque et al., 2017). Unfortunately, the conventional land use planning is often driven by political issues where more attention is given to economic growth then to consideration of ecological and microclimatic issues. However, it is widely recognized that green spaces can be beneficial for air pollution control, lowering daily temperatures, and can even promote mental well-being and facilitate social interactions (Dimoudi and Nikolopoulou, 2003, Hagen et al., 2014, Stiles et al., 2014 Duncan et al., 2019).

In one related study, Dimoudi and Nikolopoulou (2003) investigated the thermal impacts of urban greening in the urban environment, including different urban morphologies (central building being replaced by a park, increased vegetative area, different vegetation characteristics, etc.). They noted that vegetation can reduce summer air temperatures, whereby its effect is not only present within the boundaries of the green area, but it also extends beyond, particularly at the leeward side of the green area. However, replacing vegetation with different tree species did not seem to have any significant effect. Additionally, Hagen et al., (2014) investigated the effects of various urban design measures (i.e., tree planting, de-sealing of paved surfaces, extensive roof planting) on microclimate and concluded that tree planting leads to a significant reduction in both mean radiant temperature (MRT) and air temperature. Likewise, de-sealing of impervious surfaces can help lower air temperature within densely built urban areas, especially downwind of the prevailing wind direction. Roof planting equally displayed the cooling effect downwind of the wind direction, particularly when implemented on lower buildings. It is thus clear from observations reported in these studies that more informed climate-sensitive urban development approaches are needed to tackle the negative phenomena associated with urbanization. However, given the diversity of urban settlements and the complexity of their morphologies, there cannot be a uniform solution nor a single policy framework for achieving better living conditions in cities.

In this context, the present contribution investigates the resulting implications of two specific planning and adaptation strategies in regard to the urban overheating for distinct urban locations in Vienna and Linz, Austria. More specifically, we consider urban densification scenario for a quite densely urbanized district in Vienna, and urban greening scenario for a central urban area of Linz. The research is being carried out within two on-going projects: CLUDEX (Climate Change and urban densification impact exploration), funded within the framework of the Austrian Climate Research Program (ACRP) (CLUDEX 2019), and CLARITY (Integrated Climate Adaptation Service Tools for Improving Resilience Measure Efficiency), funded by the European Union's Horizon 2020 research and innovation programme (CLARITY 2019). Both studies focus on spatial modelling and numerical simulation. For these purposes, we deployed the parametric modelling environment Rhinoceros 3D and a number of built-in algorithms in the Rhino's plug-in Grasshopper for comprehensive simulation of urban microclimate. It should be noted that the present study is limited in its scope as we are only looking into the mean radiant temperature (MRT), as the selected index for the assessment of thermal comfort, as we are mostly interested in the radiant exchange of a person with his/hers immediate surroundings. Furthermore, due to the current limitations of the used computational environment, the evapotranspiration process of the vegetation is not represented in the calculations, thus only the shading effect from the trees is evaluated. However, as this is a crucial aspect when studying vegetation effects, we are currently resolving this issue for future computations.

\section{Methodology}

\subsection{Urban test areas}

This study focuses on two densely built urban areas in cities of Vienna and Linz, Austria. The area in Vienna is located in the 12th district called Meidling (longitude $16.3160^{\circ} \mathrm{E}$, latitude $48.1674^{\circ} \mathrm{N}$ ), while the area in Linz is positioned in the very centre of the city (longitude $14.2862^{\circ} \mathrm{E}$, latitude $48.3062^{\circ} \mathrm{N}$ ). The extent of these domains is depicted in Figure 1. Spatial dimension of the considered domains is $500 \times 300$ meters in case of Vienna and $400 \times 400$ meters in case of Linz. The general structure of these areas is similar. Both areas fall under the Local Climate Zone 2 (LCZ 2) category, which depicts dense mix of mid-rise buildings with few green areas, as defined by Stewart and Oke (2012). The buildings in both areas are mostly residential with grocery shops, office spaces or restaurants occupying 
the ground floors. The height of buildings ranges from 4 meters to 22 meters, with buildings being on average of 4 stories high. Roofs are flat or slabbed, covered in conventional materials (e.g., gravel, metal tiles, clay tiles).

(a)

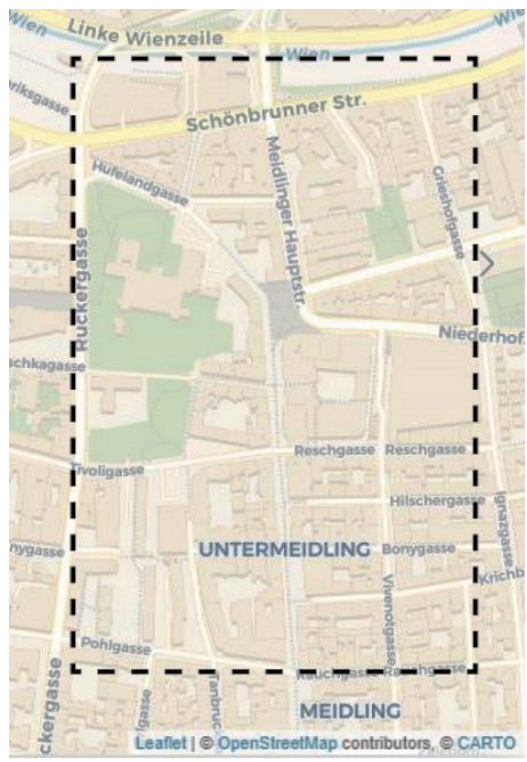

(b)

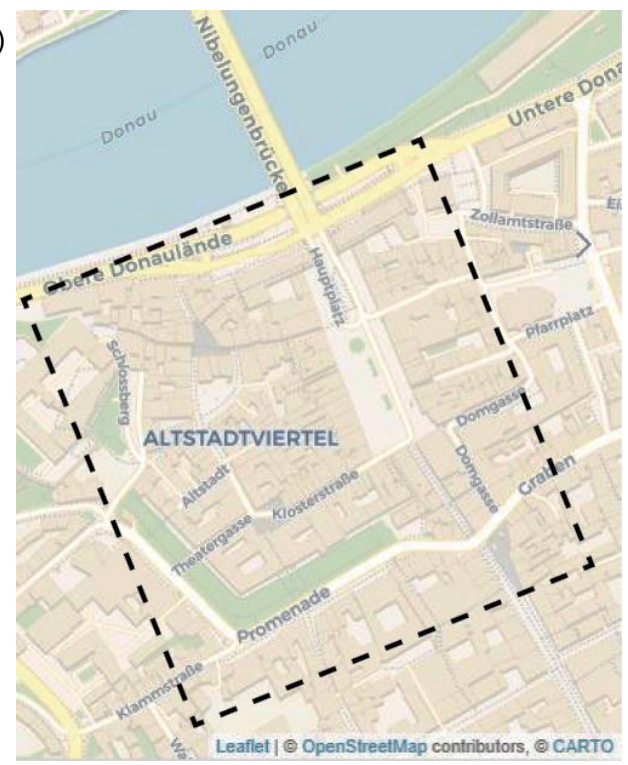

Figure 1: Case study domains: (a) Vienna's 12th district Meidling; (b) Linz's city centre (Source: open street map).

\subsection{Planned interventions}

To investigate the spatial potential and microclimatic implications of different urban transformations of existing urban areas, we considered two distinct scenarios: urban densification for the case study in Vienna, and urban greening for the case study in Linz. These interventions are aligned with planned future developments described in corresponding local urban planning and land use regulation plans.

Due to persistent population growth, the city of Vienna took into consideration alternative spatial strategies that consider inner-urban densification. The specifics regarding the potentials of such interventions are described in local zoning guidelines (LGBI 2013). Following these regulations, the maximum building height threshold is either 16 or 21 meters for the considered area. These are in accordance with essential technical constraints of buildings, i.e. structural properties, defined according to the building's vintage. Due to important considerations regarding, for example, affected energy requirements, daylight access, fire safety, air and noise pollution, resulting from urban densification and increased population, initial calculations were conducted for the whole area of Meidling district addressing some of these issues (Loibl et al., 2019). These initial calculations have shown that floor space increased for around 15\% (without attic conversion) to $25 \%$ (with attic conversion), after the densification is carried out on those buildings where the height limit was not yet met. By further multiplying the newly generated apartment units by two, considering that the average household holds two people, an estimation of the new population capacity and energy use can be carried out.

In case of Linz, according to the city's Green Space Strategy (Stadt Linz, 2013), the conservation and boost of urban green infrastructure is recognized as the main priority under ongoing urban growth. Envisioned urban green corridors are meant to attenuate the air pollution problems, resulting from industrial and traffic emissions, by acting as fresh air corridors, thus improving the overall quality of urban life. One of the targeted areas is the inner-city area where creation of vegetated surfaces will also limit the massive sealing of the ground and further contribute to reduction of heat stress and improvement of local microclimatic conditions.

\subsection{Modelling process}

3D spatial modelling was carried out within the parametric modelling environment Rhinoceros 3D (Rhino 3D 2019). Starting from the open-source digital geodata consisting of the building footprints with building height information and land-use data (Open Data Austria 2019), base case district geometry models were built using a number of built-in algorithms in the Rhino's plug-in Grasshopper. For densification scenario (as depicted in Figure 2), the upward extrusion of existing building volumes was done based on the information regarding the maximum allowed building height, as defined in the height zoning regulations for the city of Vienna (LGBI, 2013). For 
greening scenario (as depicted in Figure 3), additional row of trees was modelled in the main open square so as to investigate the effects of green corridors, based on principles defined in Green Space Strategy (Stadt Linz, 2013).

(a)

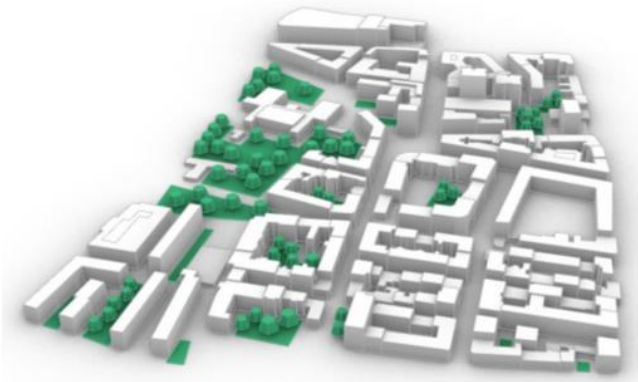

(b)

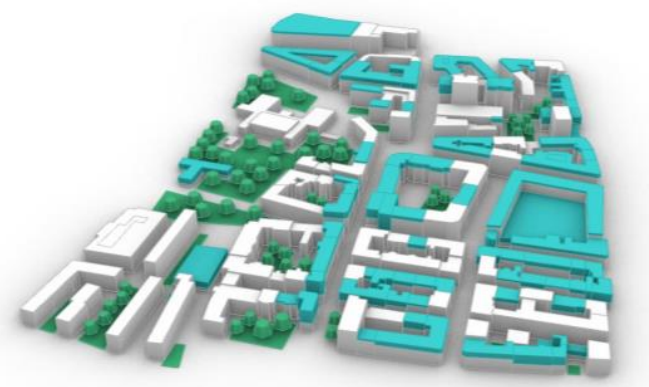

Figure 2: Vienna 3D model: (a) base case; (b) densification scenario (depicted in cyan colour)

(a)

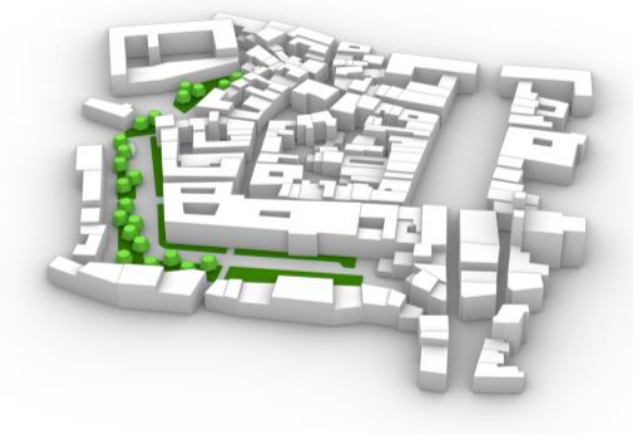

(b)

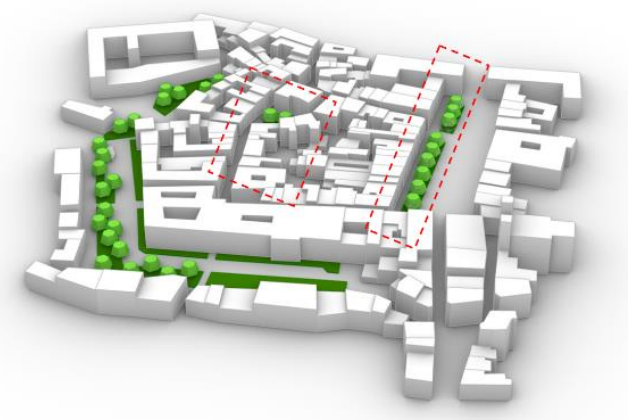

Figure 3: Linz 3D model: (a) base case; (b) greening scenario (depicted in red border).

To facilitate the respective microclimatic assessments of considered urban transformations, we deployed a number of functionalities from the Ladybug Tools available in Grasshopper (Ladybug Tools, 2019). More specifically, we deployed Ladybug and Honeybee collections from the entire family of Ladybug Tools (i.e., Ladybug, Honeybee, Dragonfly, Butterfly). To define the boundary climate conditions for 3D geometry models, we used Ladybug components to bring in the respective weather files, depicting a typical reference year (TRY) representing the year 2018 composed for both cities. These files were obtained from the official EnergyPlus weather data database handled by U.S. Department of Energy's (DOE) Building Technologies Office (BTO) (EnergyPlus Weather, 2019). The period used for the simulation efforts depicts a hot summer period (high daily temperature, cloud-free and low wind conditions) thus allowing us the investigate the performance of selected measures under a summer heat wave (Figure 4). To carry out energy simulations of 3D geometry models, we used Honeybee components which allow the definition of buildings' and ground thermal zone conditions and buildings' HVAC system. In principle, Honeybee connects the Grasshopper with validated simulation engines, such as EnergyPlus (EnergyPlus, 2019), Radiance (Radiance, 2019), THERM - Two-Dimensional Building Heat-Transfer Modeling (Therm, 2019), in order to perform advanced energy and daylight simulations, including the envelope heat flow. More details about the specific settings and operative steps involved in undertaken energy simulations may be found in Vuckovic et al., (2019). 


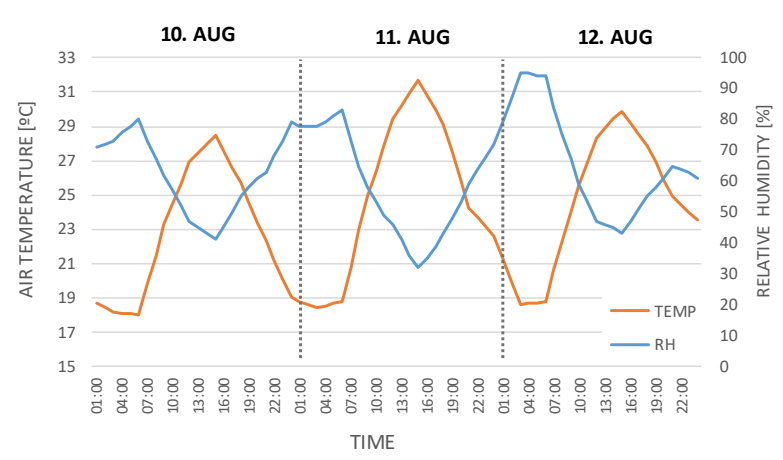

(a)

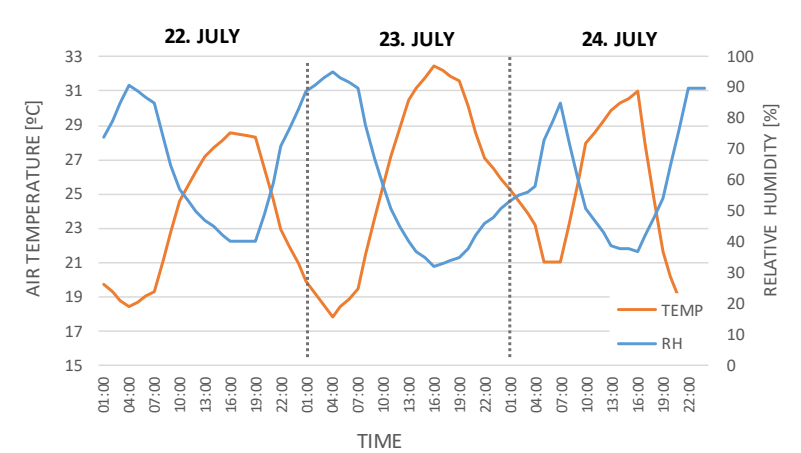

(b)

Figure 4: Selected hot summer days derived from TRY (2018): (a) Vienna; (b) Linz (Source: EnergyPlus Weather 2019).

\section{Results and discussion}

\subsection{Urban densification in Vienna}

Figure 5 illustrates the spatial distribution of MRT values at the ground surface, for both pre-densification (Figure 5a) and postdensification (Figure 5b) scenario, averaged over a 24 hour-period, starting from $7 \mathrm{AM}$ on $11^{\text {th }}$ of August 2018 . Figure $5 \mathrm{c}$ illustrates the difference map generated for the same timeframe. The results clearly show that, after the densification is carried out, newly formed taller buildings are blocking the incoming short-wave solar radiation resulting in less energy reaching and being absorbed by the ground surfaces. This also holds true in case of courtyards, especially the ones with small footprint and high height-to-width ratio, where a significant reduction in available solar gain can be observed. Our results suggest that shading accounts for a diurnal reduction of MRT of about $7.0^{\circ} \mathrm{C}$, averaged over the observed period. This is expected to lead to an improvement of outdoor thermal conditions in urban canyons, especially at the pedestrian level, as well as, to a reduction of the cooling demand for the lower floors of the buildings in summer. However, one should note that a more compact composition of the urban fabric (i.e. "deep" urban street canyons) may also affect the air flow in urban canyons. In turn, this may influence the spatial and temporal variability of thermal perception of pedestrians. This is also in agreement with a study done by Reiter (2010) where it was noted that in dense urban environments a wind protection effect is created at pedestrian's level, with wind speeds being reduced by homogeneous buildings heights. Likewise, if we consider the seasonal effects of these kinds of interventions, urban densification also brings deeper shadows during the wintertime. This is an aspect that must not be neglected as this might negatively affect the outdoor thermal comfort at the pedestrian level and may lead to the higher heating demand of buildings.

Figure 6 illustrates the day and night shares generated for a 12-hour period, starting from 7 AM on $11^{\text {th }}$ of August for daytime, and from $7 \mathrm{PM}$ on $11^{\text {th }}$ of August for night-time. In general, different thermal response can be observed. During the day, a significant cooling at the ground surface level is achieved once the densification is in place. The potential reduction of daytime MRT may be as high as $14^{\circ} \mathrm{C}$. During the night, both cooling and heating effects at the ground surface level are noted, ranging from $-0.4^{\circ} \mathrm{C}$ to $+0.4{ }^{\circ} \mathrm{C}$. The modelled night-time ambient heating effect may be due to the higher thermal mass and higher buildings' surface fraction, resulting from densification, and corresponding higher heat intake by the buildings. In addition, with the change in sky view factor and formation of deeper urban canyons, more time is needed for the long-wave radiation to reach the sky, which is only exaggerated through additional multiple reflections between building facades. This occurrence is also visible in the courtyards, as, due to their enclosed and compact composition, a greater part of the heat received during the day remains within the courtyard's boundary. However, if we consider the magnitude of these events, they are clearly of a lesser intensity than the daytime MRT differences. 

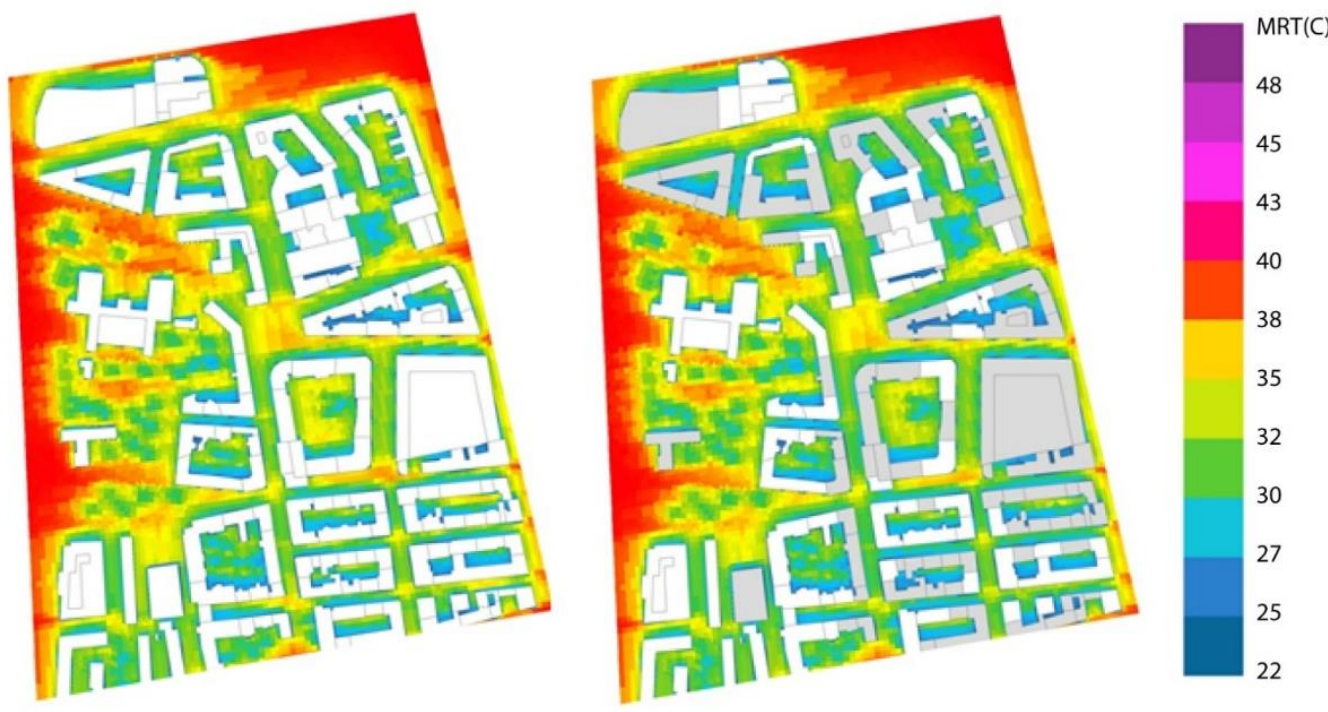

(c)
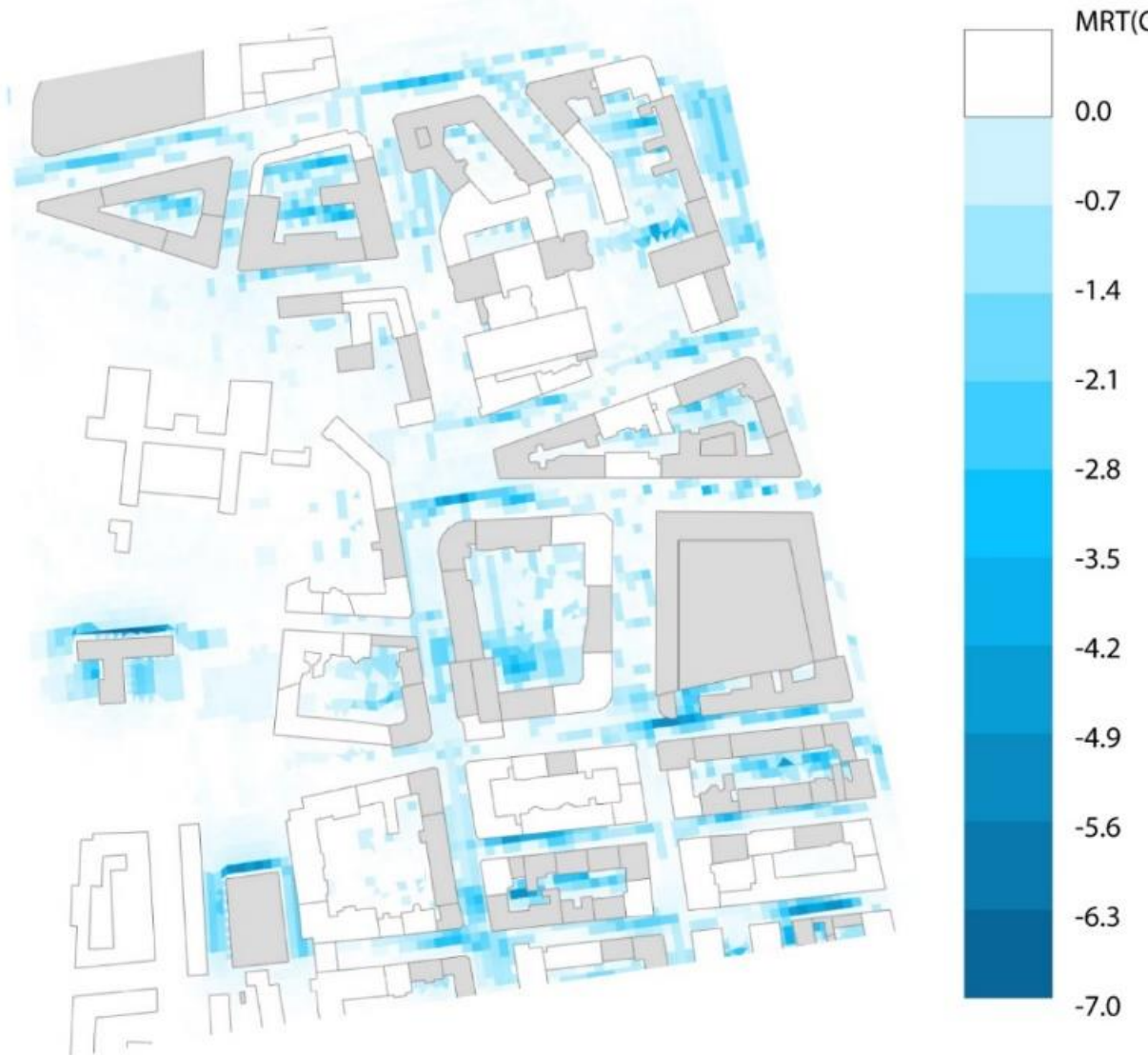

Figure 5: Spatial distribution of MRT at ground level, averaged over a 24-hour period: (a) base case; (b) densification (marked by grey rooftops); (c) difference map. 
(a)

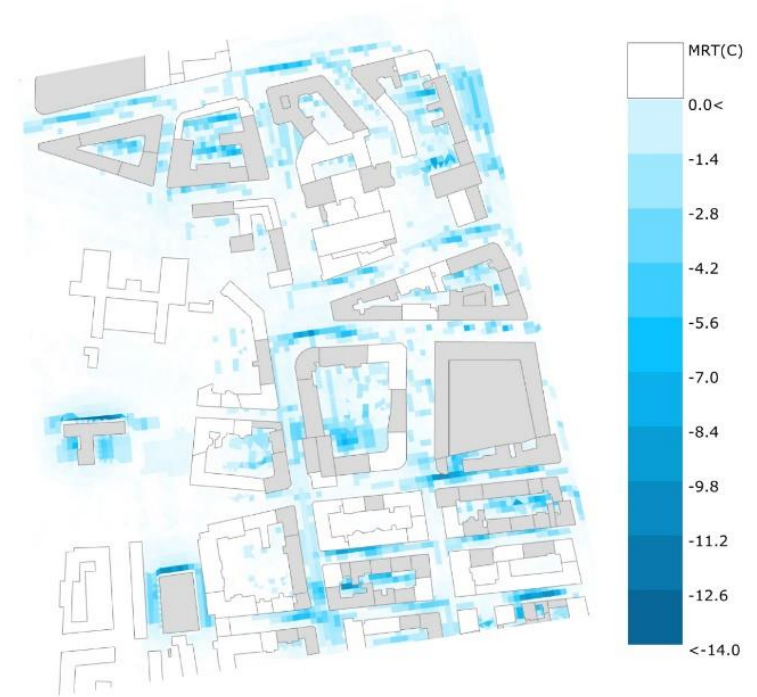

(b)

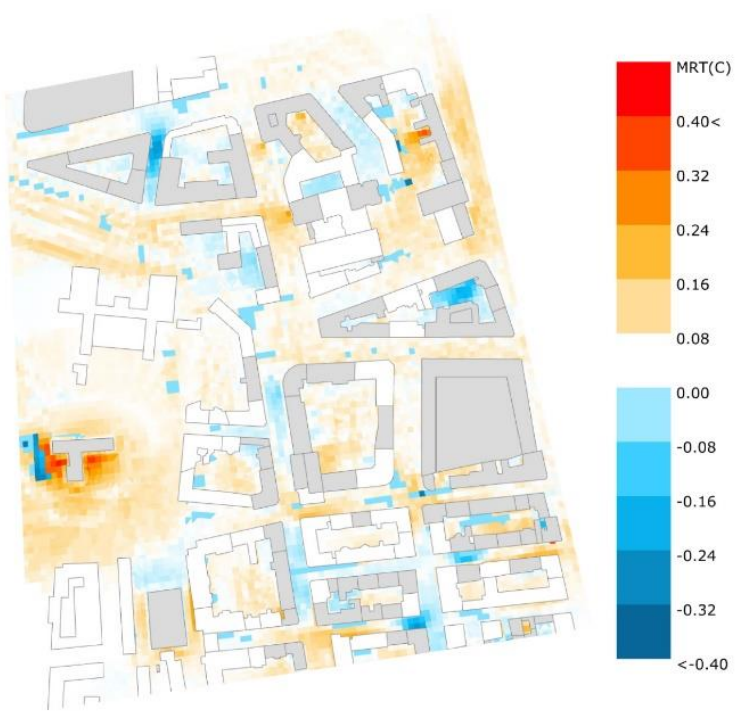

Figure 6: MRT difference maps generated for a 12-hour period at ground level for urban densification scenario: (a) daytime; (b) night-time.

\subsection{Urban densification and heat exposure at rooftop level}

Due to the unobstructed SVF (sky view factor) and overall higher solar radiation exposure at the rooftop level of newly extended buildings, the total heat gain and heat storage at this level is likewise increased. The following figures (7 and 8 ) illustrate this effect by a vertical section, depicting the dissipation of the heat from the buildings' surfaces (especially from the elevated rooftops, much more exposed to the solar radiation) heating up the surrounding air volume. Figure 7 illustrates the diurnal MRT distribution, averaged over a 24-hour period, for the existing state (the base case), while figure 8 illustrates the results for the densification scenario. The MRT above the rooftop areas are exceeding $48^{\circ} \mathrm{C}$ as indicated through dark purple colour. Table 1 provides MRT values sampled from a reference point P1 (marked in figures 7 and 8) above the newly generated taller building. Compared with figure 7 , the section of the densification scenario in figure 8 shows more air volume with MRT above $48^{\circ} \mathrm{C}$ (near the centre and east part of the section). One reason refers to the smaller distance to the rooftop emitting back-radiation. Furthermore, the higher heat dissipation is caused by increased building volumes, i.e. larger thermal mass of the taller buildings, and less shading at rooftop levels which are now fully exposed to the incoming solar radiation. In general, this leads to the higher heat gain by newly elevated rooftops having thus more heat readily available for back emission above the urban canopy layer.

Table 1: MRT values sampled from the reference point P1 marked in the vertical section from different hours during the day.

\begin{tabular}{cccc}
\hline Scenario & $\begin{array}{c}\text { Average daily MRT } \\
{\left[{ }^{\circ} \mathbf{C}\right]}\end{array}$ & 7 AM MRT [ $\left.{ }^{\circ} \mathbf{C}\right]$ & 12 AM MRT [ $\left.{ }^{\circ} \mathbf{C}\right]$ \\
\hline Base Case & 43.1 & 32.3 & 80.8 \\
Densification & 50.1 & 35.9 & 101.0 \\
\hline
\end{tabular}

\subsection{Urban greening in Linz}

In the case of Linz, the research focus was not on microclimatic effects of urban densification but of greening measures. Figure 9 illustrates the spatial distribution of MRT values at the ground surface, for both base case (Figure 9a) and greening (Figure 9b) scenario, averaged over a 24 hour-period, starting from 7 AM on $23^{\text {rd }}$ of August 2018. Figure 9c illustrates the difference map generated for the same timeframe. The results clearly show that urban trees can significantly contribute to shading from direct solar radiation. The noted diurnal reduction in MRT exceeds $11^{\circ} \mathrm{C}$. This in turn can help lower both the ambient air and ground surface temperature. The cooling effect from the trees has a potential to be further extended when taken by the air flow, especially in those instances when the trees are placed within a larger open space (e.g. an open plaza). This in principle can help reduce the spatial coverage of hot areas in the city. 
However, the enclosed composition of an outdoor space may pose some limitations to such an effect due to the inherited constraints by the surrounding geometry, as seen in Figure 9c. These observations are consistent with a study done by Tan et al. (2017) where they showed that a cooling effect of trees is more pronounced at high-SVF then at the low-SVF urban areas. Additionally, when trees are placed close to the buildings, their canopies shield the building envelope from incoming solar radiation, which is expected to lower indoor air temperature and cooling demand. In turn, this may lower the anthropogenic heat output from the buildings, a factor that is proven to affect the urban temperature rise (Santamouris, 2001).

In contrast to the urban densification scenario, urban greening seems to display a cooling effect during both night and day (Figure 10). These results were generated for a 12 -hour period between the $23^{\text {rd }}$ and $24^{\text {th }}$ of August, starting from 7 AM for daytime, and from 7 PM for night-time. The daytime cooling effect is significantly higher than the night-time effect, due to the extensive solar shielding by the tree canopy. This also can help improve outdoor thermal comfort by maintaining low surface temperature, having thus less energy available for long-wave radiation during the night-time.

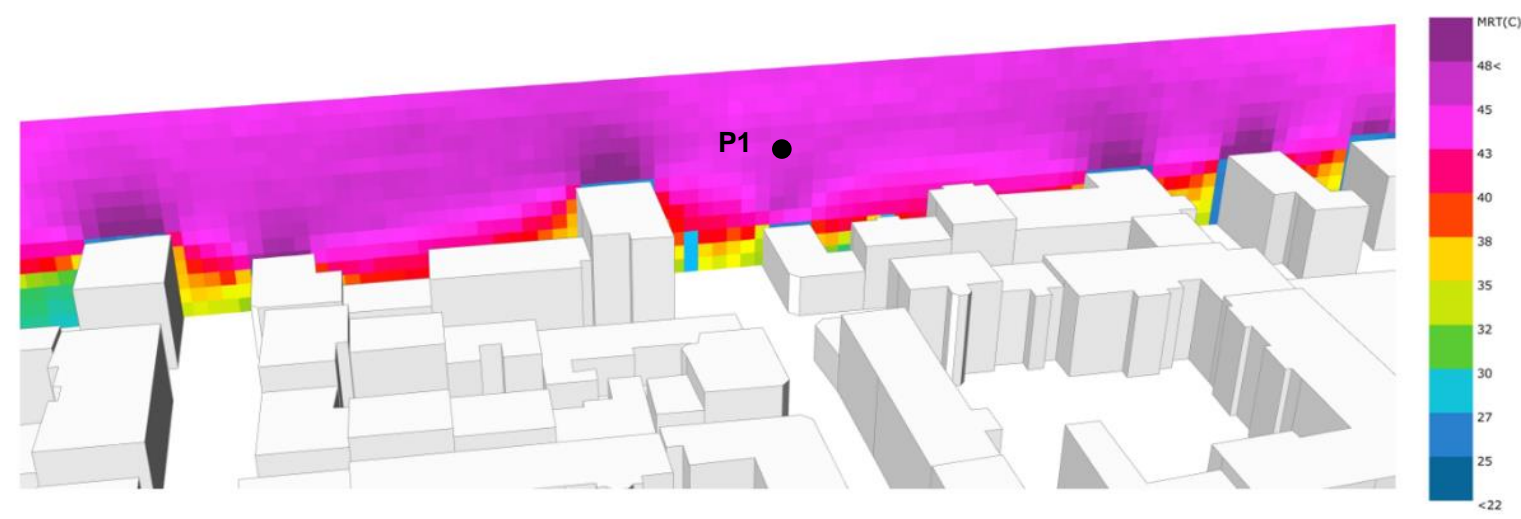

Figure 7: MRT distribution around the ground and buildings' surfaces averaged over a 24-hour period, base case scenario (vertical section through the test area from the west to the east).

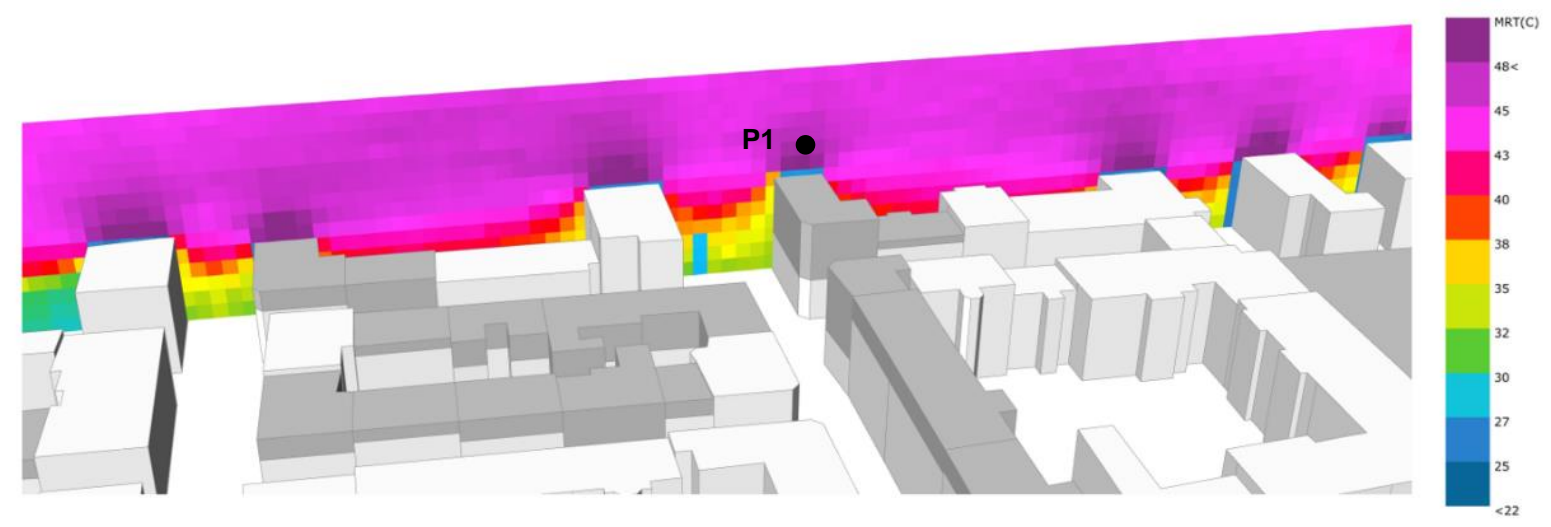

Figure 8: MRT distribution around the ground and buildings' surfaces averaged over a 24-hour period, densification scenario (vertical section through the test area from the west to the east). 
(a)

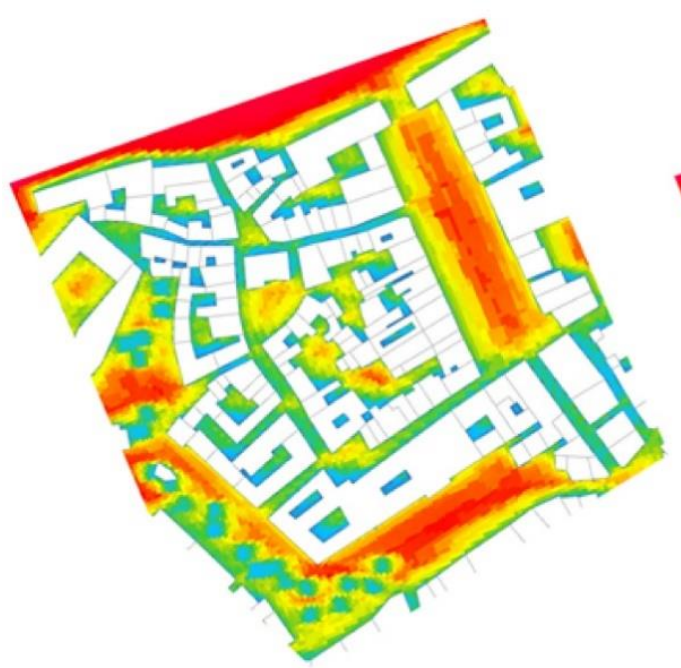

(c) (b)

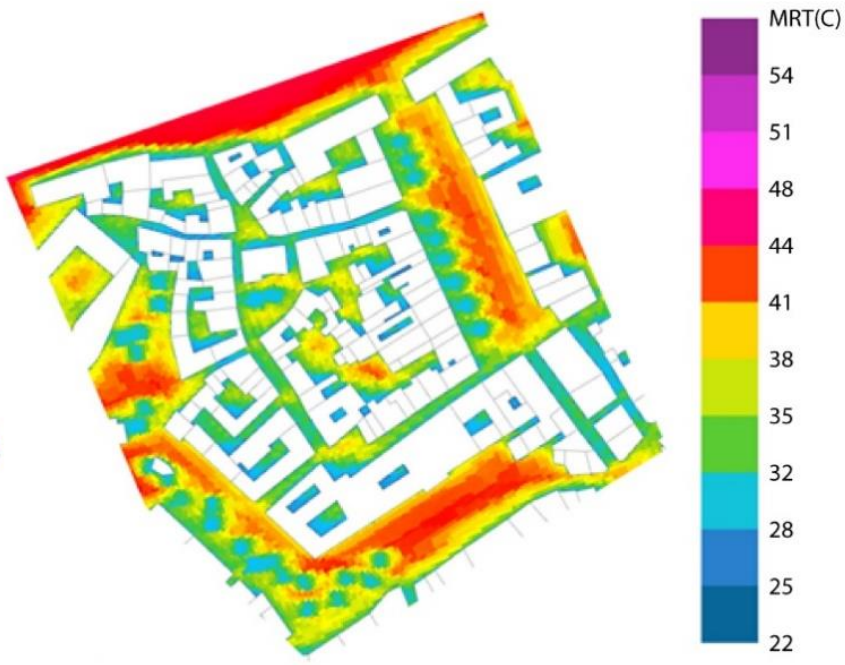

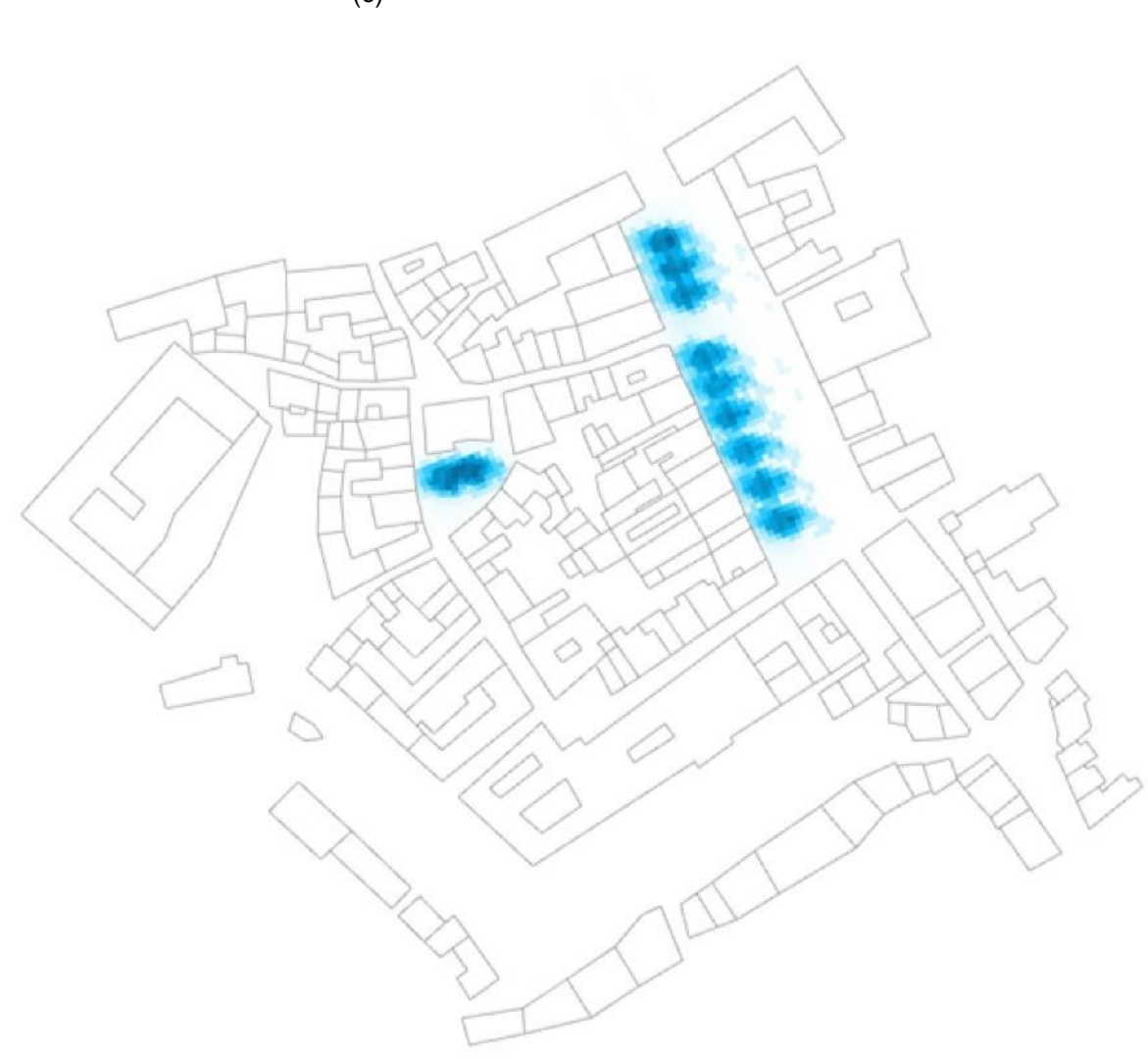

$\operatorname{MRT}(\mathrm{C})$
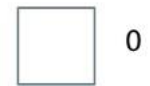

$-1$

$-2$

$-3$

$-4$

$-5$

$-6$

$-7$

$-8$

$-9$

$-10$

$-11$

$-12$

Figure 9: Spatial distribution of MRT at ground level, averaged over a 24-hour period: (a) base case; (b) urban greening; (c) difference map. 
(a)

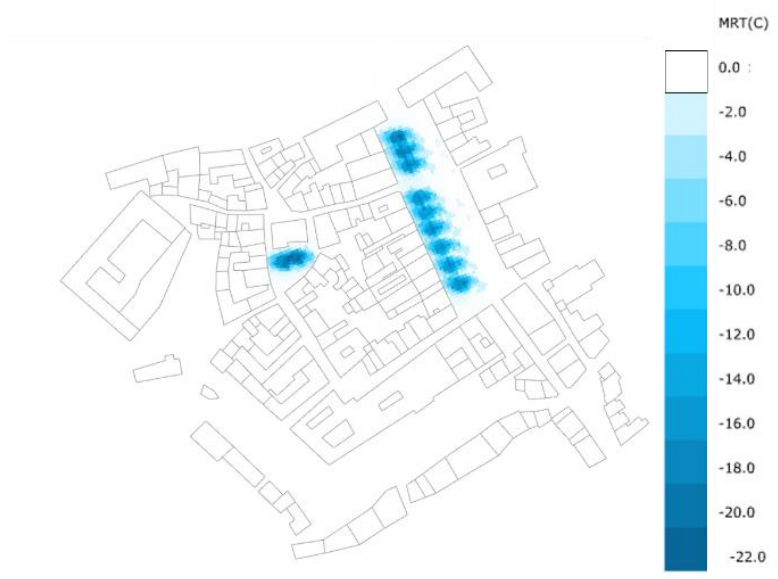

(b)

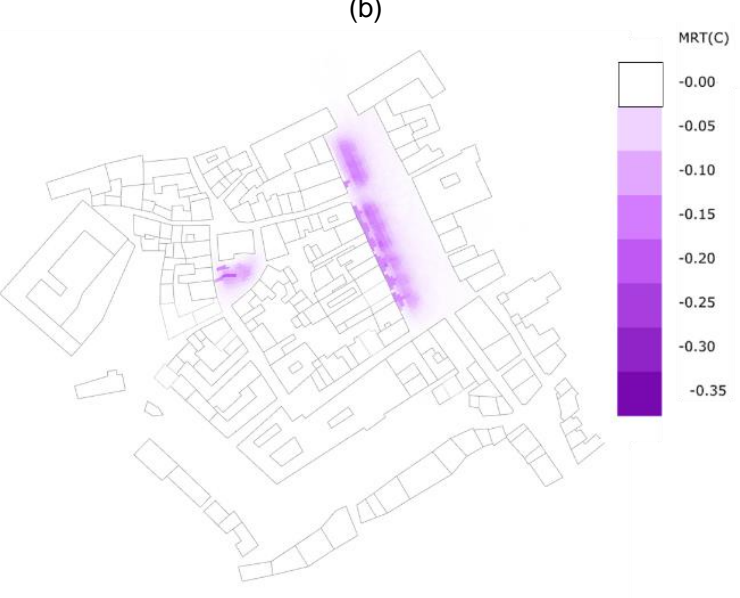

Figure 10: MRT difference maps generated for a 12-hour period at ground level for urban greening scenario: (a) daytime; (b) night-time.

\subsection{Urban greening effect on the vertical plane}

Figures 11 and 12 investigate the diurnal MRT distribution at the open plaza by a vertical section, averaged over a 24-hour period, for pre- and post-greening scenario. Figure 11 shows the detail of the open plaza for the existing state (the base case), while figure 12 illustrates the results for the greening scenario. We focus on 3 situations: (1) at the air volume surrounding a fully solar-exposed area, (2) the area which is concealed by the building shade and (3) the area under the tree. The comparison of all 3 cases clearly shows that most of the incoming solar energy gets intercepted by the tree canopy. In the case when the area marked with P1 in Figure 11 is being only influenced by the building shade (case 2, base case), the diurnal MRT is $42^{\circ} \mathrm{C}$. Figure 12 shows that, once the tree is in place (case 3 , greening scenario), the MRT is lowered to $30^{\circ} \mathrm{C}$. It can be further observed that the diurnal MRT for part of the open plaza which is being fully exposed to the sunshine (P2, case 1), the MRT can get as high as $48^{\circ} \mathrm{C}$. The shading effect extends relative to the incoming sun vectors, thus having the potential to thermally regulate a wider extent of an urban environment.

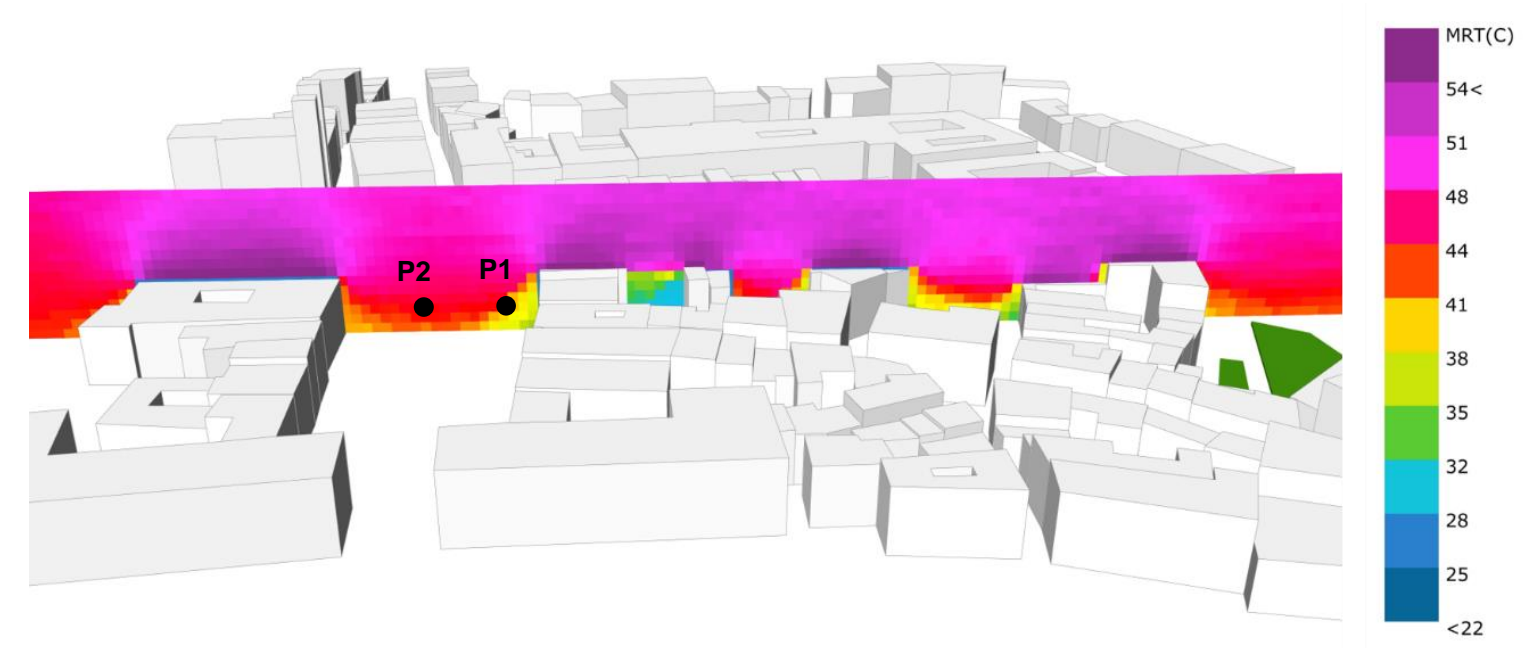

Figure 11: MRT distribution around the open plaza averaged over a 24-hour period, base case scenario. 


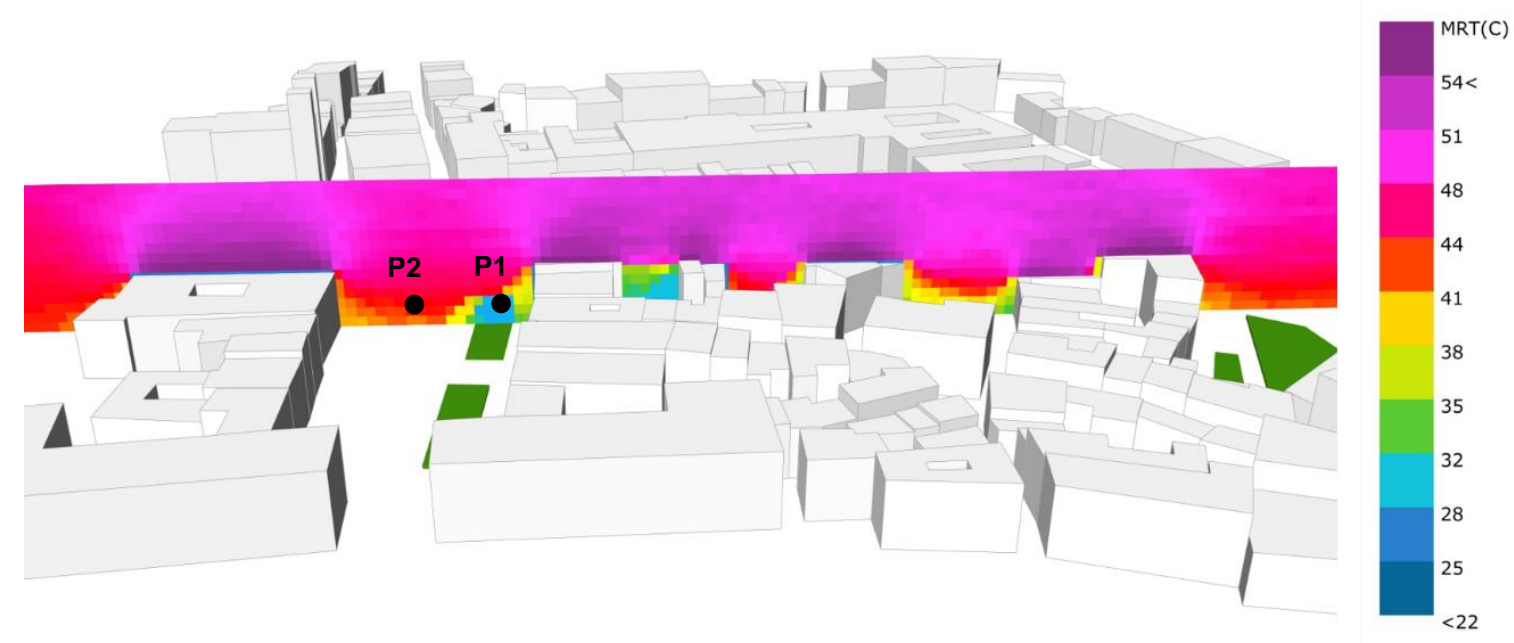

Figure 12: MRT distribution around the open plaza averaged over a 24-hour period, greening scenario.

\section{Conclusions}

We presented the first results of two on-going projects that investigate the impact of building geometry and vegetation on the outdoor thermal environment at the pedestrian level and above the rooftops (for building geometry case study) during a hot summer period. More specifically, we looked at the resulting implications of urban densification and urban trees within the context of MRT. The study was conducted for urban areas in two cities in Austria.

Our findings suggest that urban densification can help restrict solar access to the ground surfaces due to the interception of solar rays by newly formed taller buildings. This, in principle, can deepen the shadows in the urban canyon and help create thermally comfortable urban environment during summer for the pedestrians. Looking at the diurnal (24-hour) cooling effect, the noted overall reduction of MRT was about $7.0^{\circ} \mathrm{C}$. Furthermore, the energy exchange between ground floor of the buildings and the outdoor space is equally affected, due to the reduction in net solar gain of building envelope. This can potentially lower the building cooling demand and the resulting anthropogenic heat output. However, contradictory effects were noted between daytime and night-time. During the day, a significant cooling at the ground surface level was noted, leading to the potential reduction of daytime MRT of $14^{\circ} \mathrm{C}$. However, the night-time results showed both cooling and heating effects at the ground surface level, due to the higher building mass and an overall higher energy uptake. This is further visible in the vertical section, where now higher floors and rooftops of newly generated taller buildings are getting more exposed to the solar radiation, having thus more heat for long-wave emission during the night-time. This, in principle, can also affect the circulation patterns above the urban canopy layer. We can thus conclude that urban densification can be beneficial for improving the nearground thermal conditions (during summer), but its impact on total thermal environment varies with different scales. However, there is a concern that urban densification may have a reverse effect during the winter, where deeper shadows may bring the winter temperatures further down. Thus, the implementation of such an intervention should be carried out with caution, but most importantly in an informed and strategic manner, supported by a deeper understanding of local climate effects and causal factors.

On the other hand, urban greening was proven to be quite a promising strategy for improving the outdoor thermal conditions at all temporal scales. Namely, a large amount of incoming radiation in the urban canyon is captured by the tree crown during the day, which may significantly reduce the below surface and adjacent air temperature. With sufficient energy being blocked by the tree crown, less heat is being absorbed by the ground surface, affecting also the night-time long-wave emission from the ground. The cooling effect from the trees was clearly noted during both day and night. The results from the vertical section showed notable differences between a fully solarexposed area, the area which is concealed by the building shade and the area under the tree. In general, the area below the tree was the coolest of the three, with MRT being reduced for $18^{\circ} \mathrm{C}$ when compared to the fully exposed spot. Furthermore, strategic placement of the trees closer to the buildings may provide additional shading to the building envelope, which is expected to lower building cooling demand and resulting anthropogenic heat output, thus having the potential to improve air quality and overall quality of urban life. Additionally, deciduous trees (which make most of the vegetation in the city of Linz) shed all their leaves during the wintertime, allowing the sunlight to pass and improve thermal sensation of the pedestrians. 


\section{References}

CGD 2019. Available online: http://www.cgd.ucar.edu (accessed on 16 August 2019).

CLARITY 2019. Available online: www.clarity-h2020.eu/ (accessed on 16 August 2019).

CLUDEX 2019. Available online: www.ait.ac.at/en/research-fields/smart-and-resilient-cities/projects/cludex/ (accessed on 16 August 2019).

Dimoudi, A., Nikolopoulou, M. (2003). Vegetation in the urban environment: microclimatic analysis and benefits. Energy and Building 35(1), pp. 69-79. DOI: 10.1016/S0378-7788(02)00081-6.

Duncan, J.M.A., Boruff, B., Saunders, A., Sun, Q., Hurley, J., Amati, M. (2019). Turning down the heat: an enhanced understanding of the relationship between urban vegetation and surface temperature at the city scale. Science of The Total Environment 656 , pp. 118-128. DOI: 10.1016/j.scitotenv.2018.11.223.

EnergyPlus (2019). Available online: www.energyplus.net (accessed on 16 August 2019).

EnergyPlus Weather (2019). Available online: www.energyplus.net/weather (accessed on 16 August 2019).

Estoque, R.C., Murayama, Y., Myint, S.W. (2017). Effects of landscape composition and pattern on land surface temperature: an urban heat island study in the megacities of Southeast Asia. Science of The Total Environment 577, pp. 349-359. DOI: 10.1016/j.scitotenv.2016.10.195.

Flanner, M.G. (2009). Integrating anthropogenic heat flux with global climate models. Geophysical Research Letters 36(2), pp. 5. DOI: 10.1029/2008GL036465.

Hagen, K., Gasienica-Wawrytko B., Loibl W., Pauleit S., Stiles R., Tötzer T., Trimmel H., Köstl M., Feilmayr W. (2014). Smart Environment for Smart Cities: Assessing Urban Fabric Types and Microclimate Responses for Improved Urban Living Conditions. CORP 2014. http://corp.at/archive/CORP2014_33.pdf.

Ladybug Tools (2019). Available online: www.ladybug.tools/ (accessed on 16 August 2019).

LGBI (2013). Landesgesetzblatt für Wien. Available online: www.wien.gv.at/recht/landesrechtwien/landesgesetzblatt/jahrgang/2013/pdf/lg2013046.pdf (accessed on 16 August 2019).

Loibl, W., Etminan, G., Österreicher, D., Ratheiser, M., Stollnberger, R., Tschannett, S., Tötzer, T., Vuckovic, M., Walal, K. (2019). Urban Densification and Urban Climate Change-Assessing Interaction through Densification Scenarios and Climate Simulations. In Proceedings of the REAL CORP 2019, Karlsruhe, Germany, 4 April 2019.

Ma, Q., Wu, J., He, C. (2016). A hierarchical analysis of the relationship between urban impervious surfaces and land surface temperatures: spatial scale dependence, temporal variations, and bioclimatic modulation. Landscape Ecology 31(5), pp. $1139-1153$. DOI: 10.1007/s10980-016-0356-z.

Nazarian, N., Sin, T., Norford, L. (2018). Numerical modeling of outdoor thermal comfort in 3D. Urban Climate 26, pp. 212-230. DOI: 10.1016/j.uclim.2018.09.001.

Open Data Austria (2019). Available online: www.data.gv.at (accessed on 16 August 2019).

Petrović, N., Bojović, N., Petrović, J. (2016). Appraisal of urbanization and traffic on environmental quality. Journal of CO2 Utilization 16 , pp. 428-430. DOI: 10.1016/j.jcou.2016.10.010.

Radiance (2019). Available online: www.radiance-online.org/ (accessed on 16 August 2019).

Reiter, S. (2010) Assessing wind comfort in urban planning. Environment and Planning B: Planning and Design 37, pp. 857-873. DOI: doi.org/10.1068/b35154.

Rhino 3D (2019). Available online: www.rhino3d.com (accessed on 16 August 2019).

Richard, S., Gasienica-Wawrytko B., Hagen, K., Trimmel H., Loibl W., Tötzer, T., Köstl M., Pauleit, S., Schirmann, A., Feilmayr, W. (2014). Understanding the whole city as landscape. A multivariate approach to urban landscape morphology. SPOOL 1 (1), pp. 401418. DOI: $10.7480 /$ spool.2013.1.642.

Santamouris, M. (2001). Energy and Climate in the Urban Built Environment; James \& James: London, UK, 2001.

Stadt Linz (2013). Örtliches Entwicklungskonzept Linz Nr. 2 Grünlandkonzept Themen-, Ziel- und Maßnahmenkatalog. Gemeinderatsbeschluss 23.05.2013. Linz (A).

Stewart, I.D., Oke, T.R. (2012). Local Climate Zones for Urban Temperature Studies. Bulletin of the American Meteorological Society 93, pp. 1879-1900. DOI: 10.1175/BAMS-D-11-00019.1.

Tan, Z., Lau, K.K.L., Ng, E. (2017). Planning strategies for roadside tree planting and outdoor comfort enhancement in subtropical highdensity urban areas. Building and Environment 120, pp. 93-109. DOI: 10.1016/j.buildenv.2017.05.017.

Therm (2019). Available online: www.windows.lbl.gov/software/therm (accessed on 16 August 2019).

United Nations, Department of Economic and Social Affairs, Population Division (2019). World Urbanization Prospects 2018: Highlights (ST/ESA/SER.A/421).

Vuckovic, M., Loibl, W., Tötzer, T., Stollnberger, R. (2019). Potential of Urban Densification to Mitigate the Effects of Heat Island in Vienna, Austria. Environments 6(7), pp. 82. DOI: 10.3390/environments6070082. 